\title{
Awareness and Participation of Farmers in Extension Activities of Agricultural Media Resources and Extension Centre in Ogun State
}

\author{
O. P. Fawole and S. A. Tijani
}

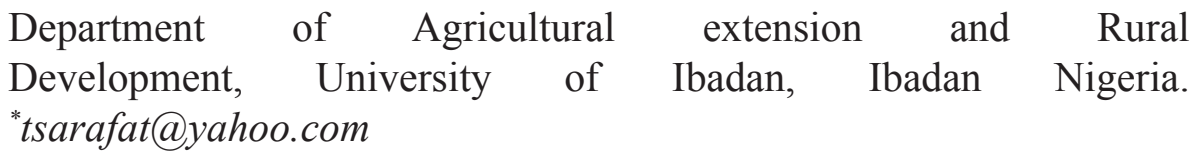

\begin{abstract}
This study assessed the extension activities of Agricultural Media Resources and Extension Centre (AMREC) of University of Agriculture Abeokuta, Ogun State. Five villages that were in active collaboration with the centre were targeted. Ten percent $(10 \%)$ of registered farmers were selected from each village given the sample size of 170 respondents. Data based on respondents awareness and participation in the extension activities of AMREC were collected through structured questionnaire and analysis was done using both descriptive and inferential statistics. The study revealed that $69.6 \%$ of the respondents were between $31-50$ years of age, $68.3 \%$ were males, $88.8 \%$ were married and $62.7 \%$ of the respondents have one form of education or the other. Majority $(82.6 \%)$ were full time farmers with $44.7 \%$ cultivating 1-2hectares while $95.0 \%$ had technical background before the inception of AMREC in the area. Greater percentage $(59.0 \%)$ of the respondents had been having contacts with extension agents once in 2 weeks. All the respondents were aware of AMREC research activities but 95\% had more awareness on market research. Respondents were aware of extension services of AMREC more than research activities and almost all the respondents were aware of input supply services of AMREC. Meanwhile, participation of respondents in research activities of AMREC was occasional while that of extension and input supply activities was regular. There is significant relationship between gender, marital status, level of education and level of participation in AMREC activities $\left(\chi^{2}=20.31\right.$, $\mathrm{p}<0.05 ; \chi^{2}=6.92, \mathrm{p}<0.05$ and $\left.\chi^{2}=21.58, \mathrm{p}<0.05\right)$. Positive relationship exists between respondents' awareness of all AMREC activities and participation in the extension activities. It can be concluded that most of the participants in AMREC activities were small scale farmers and their awareness and participation in AMREC extension and input supply activities were more than research activities. More female farmers and farmers with large hectares of land should be involved. Also, AMREC should ensure that their research work is disseminated to all farmers within their coverage areas irrespective of the specific target audience.
\end{abstract}

Key words: AMREC, activities, extension, research, input, awareness, participation 


\section{Introduction}

One of the factors which have contributed to the growth of world agricultural output is new or improved technology (Fedder and Slade, 1993). Technological change allows the production of more output per unit land, or production of the same output with smaller amount of variable inputs. However the generation of new technology is not a sufficient condition for increased output. To contribute to increase farm output and productivity, a new technology must be disseminated, adopted, and used by farmers.

Agricultural extension services are usually the main vehicle for the dissemination of technical and economic information on agriculture. Extension education is usually about change, and change in attitude to life and ways of doing things. The extension service among several other factors facilitates the adoption of more productive technology (Ruttan, 1982). Agricultural research and information services are normally under supplied in the private sector (Anderson and Holf 1993). This accounts for the emergence of public sector experiment stations and institutes more than a century ago. In Nigeria, the extension services system is the most important public service system with the widest range of responsibilities for agricultural and rural development. However the problem of inadequate trained extension workers or agents as always been one of the major constraints to agricultural development.

Agricultural media resources and extension centre is an arm of the University of Agriculture, Abeokuta which was established and charged with its extension and outreach responsibilities. Its main focus is on transferring information and technology emerging from the research centre of the university to end users -farmers. This is aimed at increasing rate of adoption and increase in food production. For Nigeria to achieve agricultural development, Ekpere (1995) observed that agricultural research in Nigeria needs to be innovative and relevant, and its result widely transferable and/or acquired by those who require it before it can contribute to development. Van-Ban and Hawkins (1996), also observed that the major role of the extension system is to transfer new technologies from researchers to the farmers and also, to help farmers form sound opinions and to make good decisions, by communicating with them and providing them with relevant information. This is what the agricultural media resources and extension centre is charged to perform at various levels from research, extension services, educating about better farming methods and improved processing technologies. Whether AMREC meet up with this responsibilities or otherwise and if the farmers aware and participate or if there exists a need to improve upon the dissemination of research result and technologies to farmers in order to create awareness and level of participation of the farmers in their extension and input supply services form the basis for this study. It is against this backdrop that this study addresses the following research objectives: 


\section{Objectives of the Study}

The study investigates the level of awareness and participation of farmers in extension activities; research, extension services and input supply services of AMREC in selected villages in Ogun state.

Specifically the study was designed to:

(i) describe the socio economic characteristics of farmers registered with AMREC in the study area;

(ii)ascertain the level of awareness of AMREC activities by the farmers registered with AMREC in the study area; and

(iii) determine the level of participation of these farmers in AMREC activities.

\section{Methodology}

The study was carried out in Ogun state, Nigeria. Ogun state is situated in latitude $06^{0} 20^{1}$ and $07^{0} 56^{1}$ North of the equator and longitude $04^{0} 35^{1}$ and $03^{0}$ $20^{1}$ East of the Greenwich Meridian. Its land area is about 16,409.26 square kilometres with an estimated population of over 2,338,570 (NPC 1991). The target population were all farmers in the operational area of Agricultural Media Resource and Extension Centre. The extension/outreach programmes of the agricultural media resources and extension centre (AMREC), started with nine villages, which were purposively selected due to their proximity to the university. To date only five villages remain in active collaboration with the centre, as the other four villages were dropped when the university relocated to its permanent site in Alabata area of Odeda local government. The number of registered farmers with AMREC in these villages was: Boodo (235); Ijemo fadipe (360); Ajura (338); Ilewo orile (355); and Ijale papa (422). Ten percent $(10 \%)$ of the total number of registered farmers were randomly selected. This gives a total of 170 farmers that participated in the study. Data were collected from the respondents using interview schedule with open and closed ended questions on farmers' socio-economic characteristics, level of awareness and participation in AMREC activities in the study area. On socio-economic characteristics, farmers were asked to indicate their characteristics such as age, sex, level of education, religion, etc. Awareness of the activities was measured by presenting the respondents with a list of AMREC activities, and respondents were asked to answer 'Yes' to the items which they were aware of and 'No' to the ones they were not aware. Scores of 1 and 0 were assigned respectively. Participation in AMREC activities was measured by asking the respondents to indicate the frequency of participation in these activities, as regularly (2), occasionally (1) and never (0). Based on the number of items aware of (for awareness) and frequency of participation in each extension 
activities and number of such activities, scores were obtained for awareness and participation in extension activities. These scores were then used in the hypotheses tested in the study.

\section{Results and Discussions}

The socio economic characteristics of respondents that were examined include age, marital status, occupation, gender, farm size, educational level, technical background, and contact with AMREC extension agents. The findings as shown in the Table 1 below revealed that $69.6 \%$ of the respondents were between $31-50$ years of age, $22.3 \%$ were 51 years and above while only $8.1 \%$ of the respondents were less than 30years. Hence many of these farmers can still be regarded to be in their active age and the implication is that food security is eminent. Majority $(68.3 \%)$ of the respondents were males, the remaining percentage were female. This result negates many rural household being headed by females due to absence of male farmers from farming work. Also, $88.8 \%$ of the respondents were married while single, widowed and divorced were few (11.2\%).

Lower percentage of female may be due to engagement of the wives in occupation different from the husband. Educational status of the respondents indicates that $62.7 \%$ have one form of education or the other; only $26.7 \%$ have no formal education. Higher literacy level among respondents will make them to understand the importance of extension to their activities and it will help in adoption of innovation being disseminated by AMREC which in turn will increase agricultural productivity. Also, majority $(67.7 \%)$ of the respondents were monogamists while others $(32.3 \%)$ were polygamists. Contrary however was the result of religion inclination with $46.6 \%$ of the respondents being Christians, 43.5\% were Muslims while only 9.9\% are traditionalists thus AMREC programme is open to all farmers irrespective of their belief. The occupational distribution of respondents revealed that majority $(82.6 \%)$ were full- time farmers, so they will be ready to adopt any practice (from AMREC) that will improve their productivity and overall standard of living because it is their main source of livelihood while others $(17.4 \%)$ were either civil servants, artisans or traders. Hence, the more reason to justify the choice of the village as the target population by AMREC.

In terms of farm size, fairly large percentage (44.7\%) cultivates 1 - 2 hectares, $28.0 \%$ cultivating 3-4 hectares while 5-6 hectares were cultivated by few $(17.4 \%)$ respondents. Thus respondents can be regarded as small scale farmers since their farm size ranges between 1-6 hectares. Years of farming experience shows that $95.0 \%$ had technical background before the inception of AMREC in the area compared with only 5.0\% that did not have any technical background. Also, greater percentage $(59.0 \%)$ had been having contacts with extension 
agents at least once in 2 weeks while others either seen extension agent once in 4 weeks, once in 2 months or once in 4 months. It implies that extension activities are not new to the farmers in the study area thus higher percentage of respondents with technical background on farming and extension activities.

Table 1: Socio-economic characteristics of Farmers $(\mathrm{N}=161)$

\begin{tabular}{|c|c|c|c|}
\hline Variables & Categories & frequency & Percentage \\
\hline \multirow{4}{*}{ Age } & $\leq 30$ & 13 & 8.1 \\
\hline & $31-40$ & 69 & 42.9 \\
\hline & $41-50$ & 43 & 26.7 \\
\hline & $51-60$ & 27 & 16.8 \\
\hline \multirow{3}{*}{ Gender } & $\geq 61$ & 9 & 5.5 \\
\hline & Male & 110 & 68.3 \\
\hline & Female & 51 & 31.7 \\
\hline \multirow{4}{*}{ Marital status } & Single & $\begin{array}{r}8 \\
112\end{array}$ & 5 \\
\hline & Married & $\begin{array}{r}143 \\
3\end{array}$ & 88.8 \\
\hline & Divorced & 3 & 1.9 \\
\hline & Widowed & 7 & 4.3 \\
\hline \multirow{6}{*}{$\begin{array}{l}\text { E d u c a t i o n a l } \\
\text { status }\end{array}$} & No formal education & 43 & 26.7 \\
\hline & Informal education & 17 & 10.6 \\
\hline & Adult education & 25 & 15.5 \\
\hline & Primary education & 46 & 28.6 \\
\hline & Secondary education & 20 & 12.4 \\
\hline & Post-secondary education & 10 & 6.2 \\
\hline \multirow{2}{*}{$\begin{array}{l}\text { Nature of } \\
\text { household }\end{array}$} & Monogamy & 109 & 67.7 \\
\hline & Polygamy & 52 & 32.3 \\
\hline \multirow{3}{*}{ Religion } & Christianity & 75 & 46.6 \\
\hline & Islam & 70 & 43.5 \\
\hline & Traditional & 16 & 9.9 \\
\hline \multirow[t]{4}{*}{ Occupation } & Farming & 133 & 82.6 \\
\hline & Trading & 6 & 3.7 \\
\hline & Civil servants & 7 & 4.3 \\
\hline & Artisans & 15 & 9.4 \\
\hline \multirow{5}{*}{$\begin{array}{l}\text { Farm size } \\
\text { (hectares) }\end{array}$} & $1-2$ & 72 & 44.7 \\
\hline & $3-4$ & 45 & 28.0 \\
\hline & $5-6$ & 28 & 17.4 \\
\hline & $7-8$ & 13 & 18.1 \\
\hline & $9-10$ & 3 & 1.8 \\
\hline \multirow{2}{*}{$\begin{array}{l}\mathrm{T} \text { e c h n i c a } 1 \\
\text { background }\end{array}$} & Yes & 153 & 95.0 \\
\hline & No & 8 & 5.0 \\
\hline \multirow{4}{*}{$\begin{array}{l}\text { Contact with } \\
\text { extension agents }\end{array}$} & Once in 2 weeks & 95 & 59.0 \\
\hline & Once in 4 weeks & 53 & 32.9 \\
\hline & Once in 2 months & 8 & 5.0 \\
\hline & Once in 4 months & 5 & 3.1 \\
\hline
\end{tabular}




\section{Awareness of AMREC's Research Activities and Extension Services}

The result on Table 2 shows that all the respondents were aware of AMREC research activities.

Table 2: Respondent's Awareness of AMREC Activities

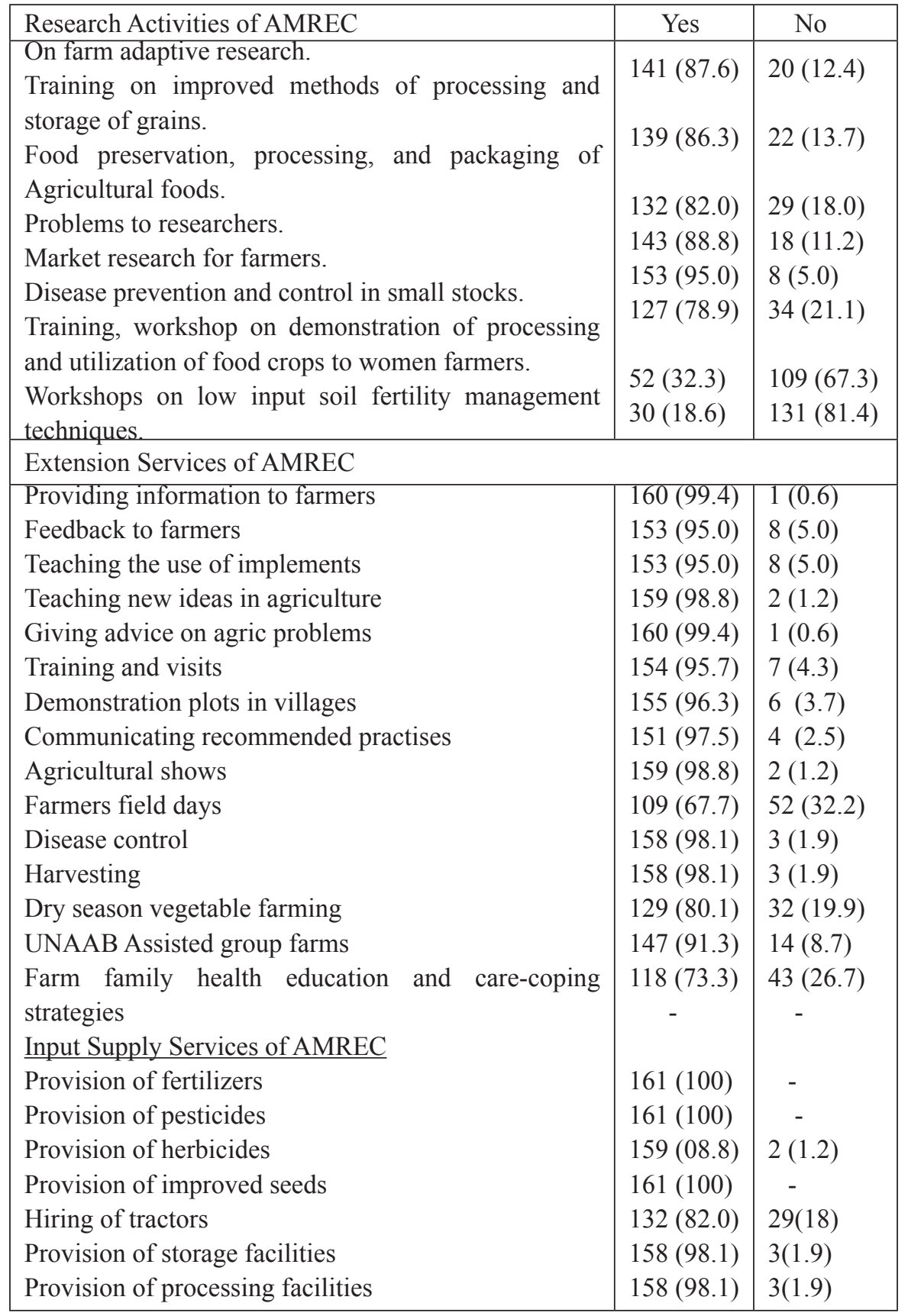


Meanwhile, greater percentage of respondents had more awareness on market research $(95.0 \%)$ where they can generate income to sustain their livelihood followed by problems to researchers $(88.8 \%)$ in order to get solution, onfarm adaptive research $(87.6 \%)$ where they can be sure of the compatibility of the innovation to their environment, training on improved methods of processing and storage of grains $(86.3 \%)$ to avoid wastage and loss especially during the peak/surplus period of production, food preservation, processing, and packaging of agricultural foods $(82.0 \%)$ and disease prevention and control in small stocks $(78.9 \%)$. This high rate of awareness could be as a result of educating and mobilizing the farmers in their respective villages towards adopting new technology in Agriculture. Moreover, the awareness and adoption of these technologies would make their products to attract high prices and they would be able to safe for the future. However, Low awareness on training and workshop for women especially on processing and utilisation of food crops as well as on soil fertility management techniques can be adduced to the fact that AMREC targeted improve agricultural production, processing and storage activities but not women specific programmes. Also, soil fertility management technique known to the majority of farmers in Nigeria is the application of fertilizer which they were getting through input supply services of AMREC hence, no necessity in undergoing training on soil fertility management techniques. In the same vein, larger percentage of respondents aware of extension services of AMREC more than research activities as also seen in Table 2, this may be due to direct impact of extension activities on respondents. Extension activities is about dissemination of useful information which AMREC has been doing hence respondents' high level of awareness. The highest awareness of extension services of AMREC by the respondents corroborates the findings of Adebayo et al., (1999) that farmers rated the roles of AMREC in extension activities to be excellent. The result on table 2 also shows that almost all the respondents were aware of input supply services of AMREC. The high rate of awareness of these services may be due to the fact that input is germane to the successful development of agriculture in Nigeria and this organisation had to encourage the farmers to organise themselves into viable cooperatives for the bulk purchase of inputs.

\section{Respondents Participation in AMREC Research Activities}

Table 3 shows that the rate of participation of the respondents in research activity of AMREC was occasionally high. The study reveals that these programmes were sometimes meant for specific target audience. For example, training workshop on demonstration of processing and utilization of food crops to women farmers $(37.9 \%$ after subtracting percentage of never participated) was meant for women that are involved in agriculture, also the low rate of participation in workshop on extending the use of cereal legume based weaning foods for lactating mothers $(37.9 \%$ as explained above) were 
for target beneficiaries such as the pregnant mothers. The information on cocoa will be meant for cocoa producers and not all farmers, which explained the reason for respondent's low rate of participation.

Table 3: Participation of Respondents in AMREC Research Services

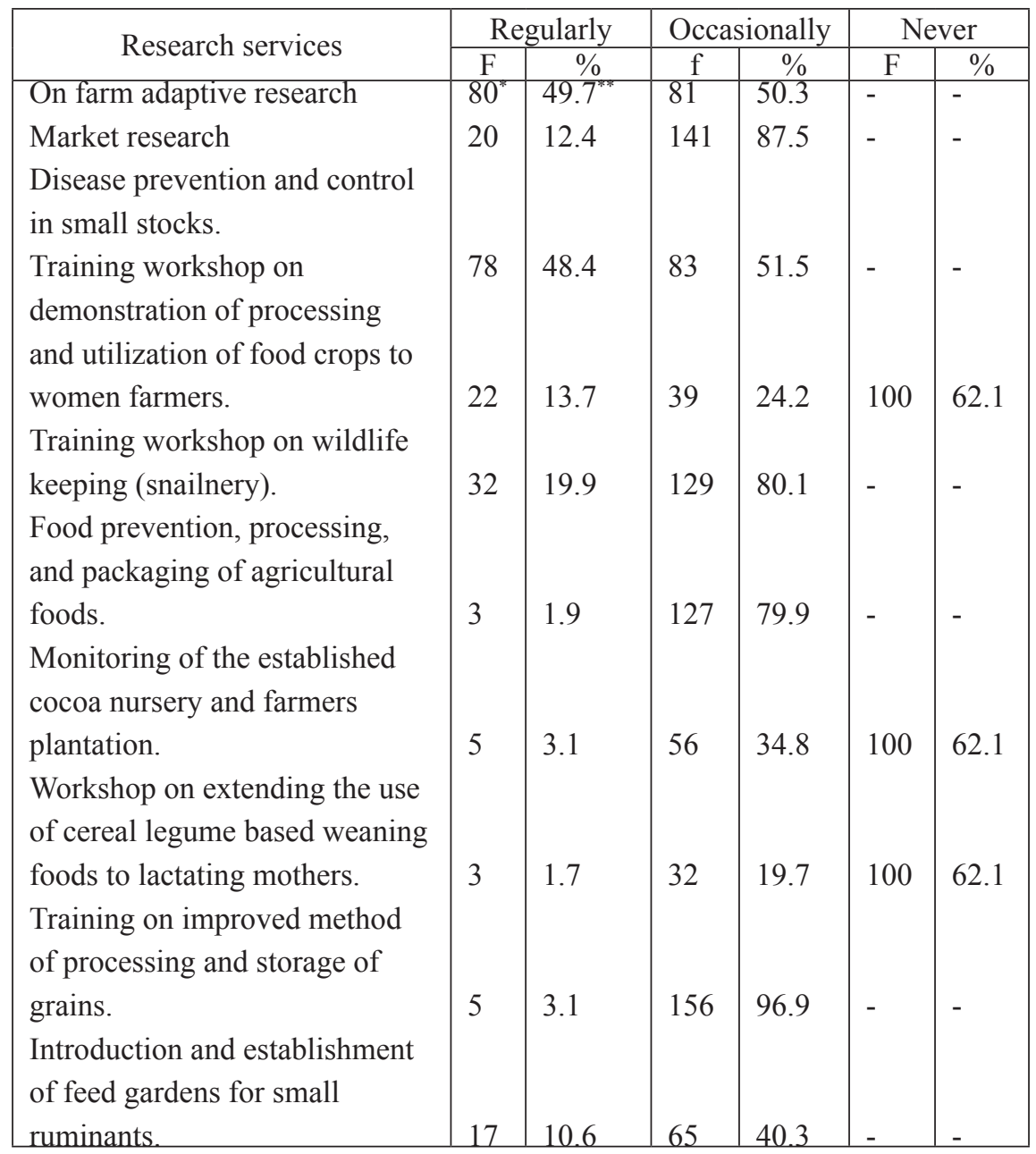

** These are row percentages

\section{Rate of participation in AMREC Extension services}

Table 3 shows that the level of participation of respondents was generally high in extension services of AMREC which include; teaching the use of implements (100\%), teaching new ideas in agriculture (100\%), disease control $(100 \%)$ arrangement of input supply (100\%) and harvesting (100\%). This high level of participation may be attributed to the extension services which tend to encourage increase in agricultural outputs of the farmers, provide opportunities for researchers, extensionist and farmers interactions. 


\section{Rate of Participation in Input Supply Services of AMREC}

The findings on Table 4 showed that the level of participation of respondents in input supply services of AMREC was regularly high. This high level of participation by the respondents may be due to timely procurement of inputs for increased production. Another perspective to this high level of participation may be due to the fact that respondents have participated in the research services and extension services and this may have prompted them to get the new idea(s) properly. This finding is consistent with Erinle (1993) which states that research extension, farmers and inputs are four important variables upon which successful farming is predicted. Each of them on its own is useless without the others.

Table 4: Respondents rate of participation in AMREC Extension services.

\begin{tabular}{|l|l|l|l|l|l|l|}
\hline \multirow{2}{*}{\multicolumn{1}{|c|}{ Extension services }} & \multicolumn{2}{c|}{ Regularly } & \multicolumn{2}{c|}{ Occasionally } & \multicolumn{2}{c|}{ Never } \\
\cline { 2 - 7 } & F & $\%$ & F & $\%$ & F & \multicolumn{1}{c|}{} \\
\hline Teaching new ideas in Agriculture & 101 & 62.7 & 60 & 37.3 & - & - \\
Teaching the use of implements & & & & & & \\
Disease control & 93 & 57.8 & 68 & 42.7 & - & - \\
Arrange input supply & 109 & 67.7 & 52 & 32.3 & - & - \\
UNAAB assisted group farms & 106 & 65.8 & 55 & 34.2 & - & - \\
Farm family health education and & & & & & & \\
care coping strategies & 80 & 49.7 & 75 & 46.6 & 6 & 3.7 \\
Harvesting & 44 & 27.3 & 77 & 47.8 & 40 & 24.8 \\
Pre-Season off campus training & & & & & & \\
for farmers & 114 & 70.8 & 47 & 29.2 & - & - \\
Cooperatives & 100 & 62.1 & 41 & 25.4 & 20 & 12.4 \\
Dry season vegetable gardening & & & & & & \\
Gender sensitization and & 43 & 26.7 & 119 & 73.9 & - & - \\
awareness seminar & - & - & 10 & 6.2 & 151 & 93.8 \\
Spacing & 103 & 64.0 & 58 & 36.0 & - & - \\
Marketing & 9 & 5.6 & 152 & 94.4 & & - \\
\hline
\end{tabular}

Table 5: Respondents Rate of Participation in Input Supply Services of AMREC

\begin{tabular}{|l|l|l|l|l|l|l|}
\hline \multirow{2}{*}{\multicolumn{1}{|c|}{ Research services }} & \multicolumn{2}{|c|}{ Regularly } & \multicolumn{2}{c|}{ Occasionally } & \multicolumn{2}{c|}{ Never } \\
\cline { 2 - 8 } & \multicolumn{1}{c|}{$\mathrm{f}$} & $\%$ & $\mathrm{~F}$ & $\%$ & $\mathrm{f}$ & $\%$ \\
\hline Provision of fertilizers & 88 & 54.7 & 73 & 45.3 & - & - \\
Provision of pesticides & 141 & 87.6 & 20 & 12.4 & - & - \\
Provision of herbicides & 124 & 77 & 37 & 22.3 & - & - \\
Provision of improved seeds & 113 & 70.2 & 41 & 25.5 & 7 & 4.3 \\
Hiring of tractors & 73 & 45.3 & 48 & 48.4 & 10 & 6.2 \\
Provision of storage facilities & 55 & 34.2 & 106 & 65.9 & - & - \\
Provision of processing facilities & 112 & 69.6 & 49 & 30.4 & - & - \\
\hline
\end{tabular}




\section{Chi-square Result for Participation in AMREC Activities and Farmers'}

\section{Demographic Characteristics}

The Table 6 shows that gender, marital status, and level of education have significant relationship with level of participation in AMREC activities $\left(\chi^{2}\right.$ $=20.31, \mathrm{p}<0.05 ; \chi^{2}=6.92, \mathrm{p}<0.05$ and $\left.\chi^{2}=21.58, \mathrm{p}<0.05\right)$. With respect to gender, it shows that more male participated in extension services than female. In case of marital status, the result shows that more married respondents were involved in AMREC activities than others while the more educated a farmer is the more is the level of participation of the farmers in AMREC activities. Also in Table 6 is the summary of the relationship between participation in AMREC activities and respondents awareness of such activities, using Pearson Products Moment Correlation. It revealed a positive relationship between respondents' awareness of AMREC research activities and participation in the activities. ( $\mathrm{r}$ $=0.60, p<0.05$ ). The result therefore shows that the farmers with high level of awareness of AMREC extension activities participated more in the activities. This therefore re-emphasizes the importance of awareness creation for any intervention programme targeting farmers in the rural area.

Table 6: Chi - Square analysis for Total Services and Demographic Characteristics of Respondents

\begin{tabular}{|l|l|l|l|l|}
\hline \multicolumn{1}{|c|}{ Variable } & \multicolumn{1}{c|}{$\chi^{2}$} & Df & \multicolumn{1}{c|}{$\mathrm{P}$} & Decision \\
\hline Gender & 20.31 & 4 & 0.00 & $\mathrm{~S}$ \\
Marital status & 6.92 & 8 & 0.00 & $\mathrm{~S}$ \\
Nature of & 7.78 & 4 & 0.30 & $\mathrm{NS}$ \\
household & 21.58 & 12 & 0.03 & $\mathrm{~S}$ \\
Level of education & 18.67 & 12 & 0.36 & $\mathrm{NS}$ \\
Occupation & & & & \\
Awareness vs & $\mathrm{r}=0.30$ & - & $\mathrm{P}=0.012$ & $\mathrm{~S}$ \\
participation in \\
AMREC activities
\end{tabular}

N:B- $\chi^{2}=$ Chi - Square, $\mathrm{df}=$ Degree of freedom, $\mathrm{P}=$ significance level at 0.05

\section{Conclusion}

Based on the findings of the study, most of the respondents involved in AMREC extension activities were male and they were married. Majority though educated but not highly educated and greater number was highly aware of AMREC extension activities, while this also influenced their participation in the extension activities. The significant relationship between gender, marital 
status and educational level of the farmers suggests that there is disparity in the level of awareness along these characteristics, since awareness has a positive relationship with level of participation of the respondents.

More female farmers should be involved and farmers with large hectares of land should also be involved so that their participation will increase food production and raise the standard of living of the entire household and the country at large. AMREC should endeavour to ensure that their research work covers all areas despite focusing on problem areas. They should embark on more enlightenment campaign on the use of agricultural innovations so as to enable the farmers get the knowledge of these innovations. The extension activities of AMREC should also focus more on the literacy aspect of extension work, so that more farmers will be able to read and write, and as such awareness will be created among a large number of respondents

\section{References}

Adebayo, K.I.A. Idowu, A.M. Omotayo, B.A Olunuga and Apantaku, S.O. (1999), Revamping the Ogun State Agricultural Development Programme through Local Finding" Papere presented at the $5^{\text {th }}$ Annual National Conference of Agricultural Extension Society of Nigeria (AESON) at the University of Nigeria Nsukka $\left(13^{\text {th }}-16^{\text {th }}\right.$ April, 1999)

Anderson, J. R. and Holf, K. (1993), Technological Change, Imperfect Markets and Agricultural Extension: An Overview, in: K. Holf, A Braverman and J.E Stiglitz (eds). The Economics of Rural Organisation, Oxford University Press, Oxford pp 471-477

Erinle, E. (1993), Transfer of agricultural research results and technology, In Shaibu, B. Adedipe, N.O. Odegbaro, O. A. Aliyu, A (eds). Towards Strengthening the Nigeria Agricultural System FINNAR, Abuja.pp53-176

Feder, G. and R. Slade, (1993), Institutional reform in India: The case of agricultural extension in: K. Holf, A. Braverman and J.E. Stiglitz (eds). The economics of rural organisation: Oxford University Press, Oxford. Pp 530-542

Ruttan, V. W. (1982), Agricultural Research Policy, University of Minneapolis Press, Minneapolis. 